\title{
(2029) Proposal to conserve the name Meiogyne against Fitzalania (Annonaceae)
}

\author{
Tanawat Chaowasku, ${ }^{1}$ Gea Zijlstra ${ }^{2}$ \& Lars W. Chatrou ${ }^{3}$ \\ 1 Netherlands Center for Biodiversity Naturalis (section NHN), Leiden University, P.O. Box 9514, 2300 RA Leiden, Netherlands \\ 2 Utrecht University, Laboratory of Palaeobotany \& Palynology, Budapestlaan 4, 3584 CD Utrecht, Netherlands \\ 3 Wageningen University, Biosystematics group, Droevendaalsesteeg 1, 6708 PB Wageningen, Netherlands \\ Author for correspondence: Tanawat Chaowasku, cyathostemma@yahoo.com
}

(2029) Meiogyne Miq. in Ann. Mus. Bot. Lugduno-Batavi 2: 12. 23 Mar 1865 [Annon.], nom. cons. prop. Typus: M. virgata (Blume) Miq. (Unona virgata Blume)

$(=\quad$ Fitzalania F. Muell., Fragm. 4: 33. Oct. 1863, nom. rej. prop. Typus: F. heteropetala (F. Muell.) F. Muell. (Uvaria heteropetala F. Muell.)

Meiogyne Miq. is a well-known genus of Asian Annonoceae with 17 species presently recognized (Van Heusden in Blumea 38: 487-511. 1994; Van Heusden in Bull. Mus. Natl. Hist. Nat., B, Adansonia 18: 77-81. 1996; Jessup in Wilson, Fl. Australia 2: 51-55. 2007; Turner in Malayan Nat. J. 61: 247-249. 2009). The number of species of Meiogyne, however, will surely increase as there are several new species to be described (D.M. Johnson, pers. comm). The genus is found from India through southeast Asia to northern Australia, New Caledonia, and Fiji (Van Heusden, 1.c. 1994, 1.c. 1996). Several genera (Ancana F. Muell., Chieniodendron Tsiang \& P.T. Li, Guamia Merr., Oncodostigma Diels, Polyaulax Backer) have been synonymised with Meiogyne on the basis of gross morphology (Van Heusden, 1.c. 1994). Meiogyne, including the synonymized genera, exhibits a corrugated or grooved area at the base of the inner side of the inner petals (Van Heusden, 1.c. 1994; Jessup, 1.c.). Moreover, the apex of those stamens located in the inner whorls (near the carpels) is usually more elongated than those located in the outer whorls (Van Heusden in Blumea Suppl. 7: 98-103. 1992; Jessup, 1.c.). These two important features also occur in Fitzalania F. Muell., an Australian endemic genus with two species (Van Heusden, 1.c. 1992: 108-109; Jessup, 1.c.: 45-46). However, the colour and appearance of the (inner) petals of Fitzalania (very dark purple and more or less boat-shaped) are somewhat different from those of Meiogyne and hence are the main reasons to still recognize this genus morphologically (Jessup, 1.c.: 45-46). In addition, one of the two species of Fitzalania, F. bidwillii (Benth.) Jessup \& al., possesses sepal-like outer petals, resembling those of Heteropetalum Benth. (now included in Guatteria Ruiz \& Pav.), Marsypopetalum Scheff. p.p., Miliusa Lesch. ex A. DC., Phaeanthus Hook.f. \& Thomson, Piptostigma Oliv., and Polyalthia Blume sensu stricto p.p.

Recent molecular phylogenetic analyses have shown that Fitzalania is nested within Meiogyne, a relationship that is strongly supported (Mols \& al. in Mols, From Miliusa to Miliuseae to Miliusoid, (Ph.D. thesis, Leiden University): 45-46. 2004). This finding is also 
confirmed by the authors (in prep.) as part of the first author's Ph.D. study to understand the phylogenetic relationships of genera in one of the major clades of Annonaceae. The genera Ancana, Guamia, and Polyaulax, which have been included in Meiogyne by Van Heusden (1.c. 1994), are also found to be embedded in Meiogyne with strong support. Unfortunately, no suitable material of Chieniodendron and Oncodostigma is available for DNA extraction. The two species of Fitzalania appeared to be sister to each other with maximum support. Therefore, the different colour and appearance of the (inner) petals are a synapomorphy of Fitzalania. The sepal-like outer petals of $F$. bidwillii is apparently an autapomorphy.

The principle of monophyly is pivotal in the classification of Annonaceae, and several genera have been re-circumscribed or newly described in the recent past. Applying this principle to the situation of Meiogyne and Fitzalania would result in the transfer of species of Meiogyne to Fitzalania, according to Art. 11.3 of the International
Code of Botanical Nomenclature (McNeill \& al. in Regnum Veg. 146. 2006), as Fitzalania antedates Meiogyne.

However, there are good reasons to conserve the name Meiogyne against Fitzalania. Firstly, the former genus contains many more species. Secondly, Meiogyne is better known as it has a considerably larger distribution area covering many more countries. Finally, Meiogyne has lent its name to a dimeric sesquiterpenoid, meiogynin A, isolated from the bark of Meiogyne cylindrocarpa (Burck) Heusden, which has significant potential as an anti-cancer agent (Litaudon \& al. in J. Nat. Prod. 72: 480-483. 2009; Fotsop \& al. in J. Org. Chem. 75: 7412-7415. 2010). Consequently, to maximize the stability of the names, it is appropriate to conserve Meiogyne against Fitzalania. Whereas at least 17 new combinations would be required if this proposal is not accepted, only two new combinations will be necessary (from Fitzalania to Meiogyne) if it is accepted. 